\title{
Picture yourself: Self-focus and the endowment effect in preschool children
}

\author{
Bruce Hood $^{a}{ }^{a}$, , Sandra Weltzien ${ }^{a}$, Lauren Marsh ${ }^{a}$, Patricia Kanngiesser ${ }^{b}$ \\ a Bristol Cognitive Development Centre, School of Experimental Psychology, University of Bristol, Bristol, UK \\ ${ }^{\mathrm{b}}$ Department of Developmental and Comparative Psychology, Max-Planck-Institute for Evolutionary Anthropology, Leipzig, Germany
}

\section{A R T I C L E I N F O}

\section{Article history:}

Received 18 August 2015

Revised 21 March 2016

Accepted 25 March 2016

\section{Keywords:}

Self-focus

Ownership

Endowment effect

Extended self

\begin{abstract}
A B S T R A C T
When an object comes into possession, the owner will typically think that it is worth more than it did before they owned the item in a bias known as the endowment effect. This bias is particularly robust in Western societies with independent self-construals, but has not been observed in children below 56 years of age. In three studies, we investigated whether endowment effect can be induced in younger children by focusing their attention on themselves. 120 children aged 3-4 years evaluated toys before and after a task where they made pictures of themselves, a friend or a neutral farm scene. Over the three studies, children consistently evaluated their own possessions, relative to other identical toys, more positively following the self-priming manipulation. Together these studies support the notion that possessions can form part of an "extended self" from early on in development and that the endowment effect may be due to an attentional self-bias framing.
\end{abstract}

(c) 2016 The Authors. Published by Elsevier B.V. This is an open access article under the CC BY license (http:// creativecommons.org/licenses/by/4.0/).

\section{Introduction}

Why is psychological ownership so important? In many ways, ownership is part of our individual identity. As James (1890) noted, our sense of self is largely based on our possessions and what we can claim ownership over.

"A man's Self is the sum total of all that he CAN call his, not only his body and his psychic powers, but his clothes and his house, his wife and children, his ancestors and friends, his reputation and works, his lands and horses, and yacht and bank-account".

[James, 1890, p. 291]

Drawing on the work of James, Belk (1988) posited the "extended self" hypothesis that maintains that in individualistic societies, we regard possessions as an extension of self. Of particular interest is our psychological attachment to material possessions that can sometimes lead to practices and beliefs, which reflects the symbolic value we place on objects (Ferraro, Escalas, \& Bettman, 2011). From the earliest examples in pre-history where the deceased were buried with their possessions, to conspicuous consumption in modern consumer behaviour, Belk considers possessions as central to the concept of self.

\footnotetext{
* Corresponding author.

E-mail address: bruce.hood@bristol.ac.uk (B. Hood).
}

Our possessions thus serve as ostensive markers for selfidentity. When we take possession of objects they become "mine" - my coffee cup, or my telephone. This is one reason why ownership plays an important role in social development. Initially infants do not exhibit a coherent sense of ownership for material possessions other than the sentimental objects such as blankets and teddy bears that are considered unique and irreplaceable (Hood \& Bloom, 2008). In the case of non-sentimental objects, children start to identify owners of familiar objects between 18 and 24 months of age (Fasig, 2000) and soon after begin to use possessive pronouns like "mine" and "yours" (Hay, 2006). Young preschoolers already understand different rules of ownership (Friedman \& Neary, 2008; Kanngiesser, Gjersoe, \& Hood, 2010) and their normative implications (Rossano, Rakoczy, \& Tomasello, 2011). Importantly, Levine (1983) has argued that the emerging sense of self is accompanied by increased use of personal pronouns and ownership expressions of "mine" related to objects.

The developing relationship between self-identity and possessions may also explain "one of the most important and robust empirical regularities" of economic behaviour (Loewenstein \& Issacharoff, 1994) namely the "endowment effect" (Thaler, 1980). In a classic study, one group of students were given mugs and asked if they would like to trade for a chocolate bar. In a second group of students the allocations were reversed. Very low trading rates were observed in both groups $(\sim 10 \%)$, despite both objects being equally attractive (Knetsch, 1989), demonstrating that 
ownership of an object increases our subjective valuation of it. This effect has been replicated numerous times and manifests both as a reluctance to trade and as a difference between buying and selling prices (Bar-Hillel \& Neter, 1996; Carmon \& Ariely, 2000; Hoorens, Remmers, \& van de Riet, 1999).

Economists commonly consider the endowment effect to be a violation of standard rational choice theory and the manifestation of a "loss aversion" bias because sellers should ignore ownership when trading for equally valued items (Kahneman \& Tversky, 1979). However, a recent review of the endowment effect has shown that it can no longer solely be attributed to a traditional loss aversion account (Morewedge \& Giblin, 2015). When owners and buyers are considering transactions there are a multitude of factors that enter into the decision-making process including the positive and negative features of the goods, transaction utility, the cost of new or used alternatives, opportunity costs and nontransferrable associations.

One of the key factors of non-transferable associations is psychological ownership, which is consistent with the "extended-self hypothesis" whereby objects are valued because of the association they have with the owner (Belk, 1988). Attempting to disentangle the competing accounts of loss aversion and extended-self, Morewedge, Shu, Gilbert, and Wilson (2009) compared values of mugs given by sellers, buyers who already owned an identical mug, and buyers who did not. They demonstrated that the endowment effect disappeared when a buyer already possessed an identical mug, indicating that the endowment effect was not due to loss aversion and was more consistent with an extended-self account. This could arise from a mechanism whereby evaluations of possessions depend on evaluations of the self (Gawronski, Bodenhausen, \& Becker, 2007; Weiss \& Johar, 2013). The bias may also reflect cultural norms regarding selfidentity and possessions, as East Asian students were found to have smaller endowment effects than Western students - an effect that could be mimicked by priming students with independent or interdependent self-focus (Maddux et al., 2010).

These cultural effects implicate a role for developmental processes in shaping how much we value our possessions. Western children as young as two years will indicate that they like toys allocated to them best - even when identical objects owned by an adult or no-one are available (Gelman, Manczak, \& Noles, 2012). Yet, the endowment effect as assessed through trading biases, when children are reluctant to swap for an equally attractive alternative, does not appear in Western children until 5-6 years of age. Although the one study of the endowment effect in children did not look at preschool children (Harbaugh, Krause, \& Vesterlund, 2001), we have previously tried unsuccessfully to establish the presence of the endowment effect in younger children (Kanngiesser, 2012). Thus, while a preference for possessions may be observed in preschoolers, previous studies have not yet demonstrated that this preference is an endowment effect which manifests as increased valuation and can be attributable to psychological ownership.

Given evidence that explicit manipulations of self-focus have dramatic effects on adults' valuation of possessions from different cultural backgrounds (Maddux et al., 2010), we wanted to investigate whether self-focus manipulations would be effective in young preschoolers and influence their evaluation of objects. In the present set of studies, motivated by the Belk's extended-self hypothesis, we adapted the self-construal paradigm for adults (Maddux et al., 2010) into one suitable for preschool children using a simple picture construction task that either focused the child's attention on themselves, others or on a neutral farm scene. Our reason for using a portrait construction manipulation was based on two lines of evidence. First, mirrored reflections have been shown to trigger self-focus and conscientiousness in both adults and children
(Beaman, Diener, \& Klentz, 1979; Diener \& Wallbom, 1976). Second, in adults, constructing an online avatar leads to increased self-focus and the closer the resemblance of the avatar, the more the self-focus (Vasalou, Joinson, \& Pitt, 2007). We reasoned that as children lack the prerequisite manual skills for drawing a self-portrait, constructing an avatar using Velcro segments was a reasonable method to generate self-focus. The selection of a friend or sibling for the other portrait task was based on the adult study where interdependence was focused by asking participants to write about friendships and camaraderie (Maddux et al., 2010).

We measured relative changes in object evaluation using a fivepoint rank liking-scale and determined whether there were any consistent changes in evaluation from the point in time before a toy was allocated to after the child had completed the picture construction task. Although the adult endowment effect studies have used monetary value as a dependent measure, preschoolers do not understand concepts of financial worth which makes this measure inappropriate for our sample (Berti \& Bombi, 1981). We reasoned that evaluation based on liking was a proxy for children's value judgments.

Children evaluated (1) their own toy, (2) an identical toy belonging to the experimenter (or no-one) and (3) a control object. We chose to use identical objects because we wanted to avoid individual biases towards different toys. This also sets up the studies to be the most stringent test of the endowment effect possible (i.e., it could not be attributed to the objects' surface properties). Although identical objects should have equal value, we have previously shown that 5-year-olds will value identical goblets differently depending on whether they believe the object to have a previously famous owner (Hood \& Bloom, 2008).

We also included a trading measure (similar to Harbaugh et al., 2001) and offered children the opportunity to swap for the experimenter's (or no-one's) identical toy. Preschoolers are noted for their reluctance to share and so we expected that this may manifest in their resistance to trades unless they had been induced to think about others. Unlike previous studies, trades were real rather hypothetical scenarios involving temporary lending (Diesendruck \& Perez, 2015).

We hypothesized that self-focus following the picture completion task would produce a significant increase in the valuation of toy allocated to the child more so than an other-focus and a neutral farm completion task. Furthermore, we predicted that any selffocus effects would be specific to the child's owned toy and not for the experimenter's nor the control toys. We also expected that children would be more reluctant to trade after completing the self-focused task compared to the other-focused task.

\section{Study 1}

\subsection{Material and methods}

\subsubsection{Participants}

Each condition contained 20 UK children. This sample size was based on pilot studies conducted in Norway by the second coauthor as part of a student project to establish the liking-scale methodology. Comparing the change in valuation of a toy allocated to the child in the self-focus condition with the other condition produced a large effect size $(d=0.852)$. We calculated that if we ran an equivalent study, we would need a sample size of 18 or more per group to have sufficient power ( 0.8 or greater).

Study 1 had three conditions (self, other, neutral) requiring 60 three-to-four-year-olds $\quad\left(M_{\text {age }}=48.38\right.$ months, $\quad S D=6.03$, range $=37-57$ months; 30 female). Eight additional children were tested but excluded from analysis because they (a) failed to pass the initial trading controls $(n=2)$, (b) failed to understand the 
pre-test scale measure $(n=5)$, or (c) failed to pass the equality test $(n=1)$. Parents gave written, informed consent prior to the start of the study. All children were tested individually in quiet rooms.

\subsubsection{Design}

The study employed a mixed design with picture-focus (self, other, or neutral farm) as a between subjects factor and toy owner (child or experimenter) as a within subjects factor. Twenty children were randomly assigned to each picture-focus condition. Order of valuation of child's and experimenter's toys was counterbalanced across participants. The dependant variable was the change in valuation of child's and experimenter's toys following item endowment and picture construction.

\subsection{Procedure}

Each session started with trading-control trials to check children's ability to trade or to inhibit trading where appropriate. In trading trials, the child was allocated a scrap of paper and asked if they would like to keep the paper or swap for a sticker (the reverse allocation was used for non-trading trials). The order of trading and non-trading trials was counterbalanced. If children failed the initial control trials, they were given two additional trading, and non-trading trials, respectively.

Next, the children were familiarized with a five-point "smileyscale" that was used to assess the relative worth of objects throughout the study. The scale consisted of five card faces attached to a board with Velcro, with expressions ranging in valence from very happy to very unhappy (see Fig. 1a). The experimenter explained each of the five expressions, removed the faces from the board and randomly placed them in front of the child. The experimenter attached the most unhappy face on the scale, and asked the child to rebuild the scale independently. If necessary, the experimenter gave one more demonstration. Only children who passed the trading controls and the smiley scale familiarization took part in the study.

Following this, the experimenter placed a set of five objects on the table, consisting of an unattractive object (a scrap of paper), a control toy, two identical spin-top toys and a highly attractive toy (Fig. 1b). The control toy was always a small plastic figure which was judged to be roughly equivalent in attractiveness to the identical spin-top toys. First, the experimenter demonstrated rating of the objects by using the smiley scale and explaining her decisions ("I like this toy the best, I'll put it on the most happy face"). The child was then asked to rate a new set of five objects, again including an unattractive object, a control toy, a highly attractive toy, and two identical spin-top toys (later used in the endowment test). Children who failed to show an understanding of the rating system (for example stating: "I do not like this toy", but placing it on a happy face) or children who failed to rate the identical toys equally were excluded.

The initial valuation of the spin-top toys and the control toy was recorded. The identical spin-top toys were then used as endowment objects: one was given to the child ("This is yours now. You get to keep it") and the other was kept by the experimenter ("This is mine. I get to keep this one"). Both toys were then placed in view, but out of reach, on the table (Fig. 1c). Next, the child participated in one of three picture construction conditions: self-focus, other-focus, or a neutral farm condition.

In each picture task, the child was told to construct a picture using a standard set of materials and a semi-structured script: a background template (either a human figure for self- and otherfocus or a farm scene for the neutral focus), and a number of Velcro-accessories (see Fig. 1d). In the self-focus condition, children made a picture of themselves and were encouraged to select their hair style, their clothes and their toys from the accessories, to (a) Smiley Scale Familiarization

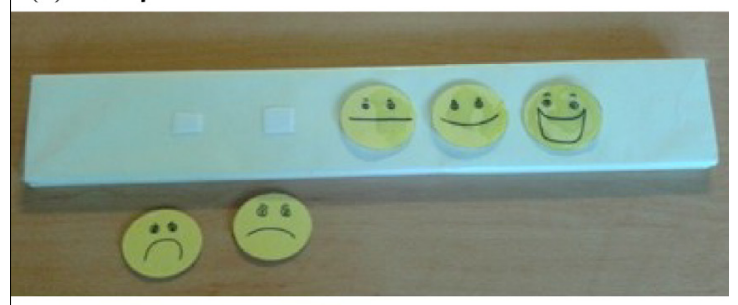

(b) Initial Object Evaluation

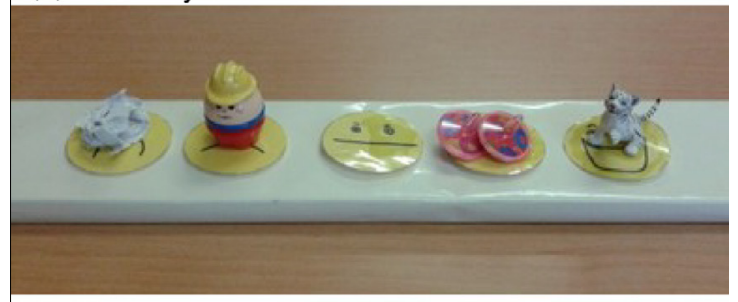

(c) Object Allocation

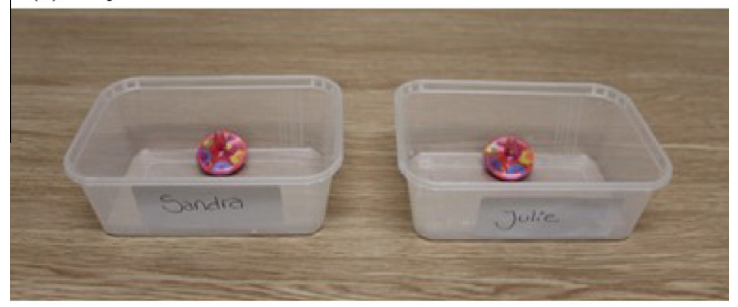

(d) Picture Construction Task

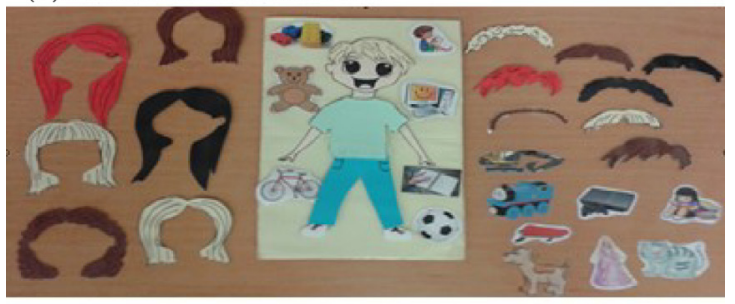

(e) Object Re-Evaluation

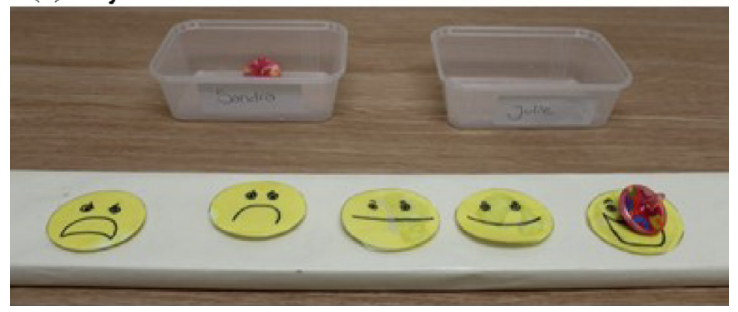

Fig. 1. Sequence of procedures for the (a) familiarization, (b) evaluation, (c) allocation, (d) picture construction and (e) re-evaluation.

further focus the child's attention on her/his self, the experimenter used second person pronouns 'you', 'your' and the child's name whenever apt and care was taken to avoid third person pronouns. In the other-focus condition, the child made a picture of their best friend or sibling using the same accessories used in the self-focus condition. To focus the child's attention on others, the experimenter used third person pronouns 'he/she', 'his/her' and the friends/siblings' name whenever apt (again care was taken to avoid second person pronouns). In the neutral-focus condition, children were encouraged to make a picture of a farm by adding the farm animals to the picture. The experimenter was careful to avoid use of all personal pronouns. 
Following the picture construction task, the child was asked to value the experimenter's toy, the control toy and their own toy once again using the smiley scale (Fig. 1e). The order of these ratings was counterbalanced across participants. Finally, the child was asked whether they wanted to keep their toy or swap for the experimenter's toy.

\subsubsection{Data scoring and preliminary analyses}

Children's valuations and trading behaviour were coded from videotape. Children's valuation of the two identical spin-top toys and the control toy on the five-point smiley-scale were scored from 1 for the most unhappy face to 5 for the most happy face. It is important to note that all children's initial valuations of the spin-top toys were always equal but to account for differences in initial valuations between participants, we calculated value-change-scores for each of the toys by subtracting the initial valuation from the final valuation for each toy (positive valuechange-scores indicating an increase in value, a zero score indicating no change). To examine the effects of priming on value-change for the two identical endowment toys, a mixed ANCOVA was conducted. Toy owner (child or experimenter) was entered as a repeated measures factor and picture type (self-focus, otherfocus, neutral-focus) and gender were entered as a between subjects factors. Additionally, child age was normalized and entered as a covariate into the model. A secondary analysis was conducted on the value-change scores for the control toy. This was conducted to check that children did not systematically change their valuation of toys when asked the same question twice, and also to check that the priming manipulation did not have a general effect on toy valuation. The order of valuation of the endowment objects had no effect on value change scores so all analyses are collapsed across this variable.

Preliminary analyses showed that time spent on the picture construction task did not differ significantly across conditions ( $F$ $(2,57)=0.36, \quad p=0.70, \quad \eta_{p}^{2}=0.01, \quad M_{\text {self }}=223.60 \mathrm{~s}, 95 \% \mathrm{CI}_{\text {self }}=$ $[212.30,234.90] ; M_{\text {other }}=229.70 \mathrm{~s}, 95 \% \mathrm{Cl}_{\text {other }}=[218.40,241.00]$; $\left.M_{\text {neutral }}=230.85 \mathrm{~s}, 95 \% \mathrm{Cl}_{\text {neutral }}=[219.55,242.15]\right)$. In addition the experimenter's use of second person pronouns during self-focus and of third person pronouns during other-focus did not differ significantly, $\left(t(38)=0.31, p=0.76, d=0.01, M_{\text {self }}=33.30,95 \% \mathrm{Cl}_{\text {self }}=\right.$ $\left.[32.17,34.43] ; M_{\text {other }}=33.05,95 \% \mathrm{Cl}_{\text {other }}=[31.92,34.18]\right)$.

\subsection{Results}

We found a significant interaction between picture construction condition and toy owner $\left(F(2,53)=4.83, p=0.01, \eta_{p}^{2}=0.15\right)$. Specifically, following self-focus, children increased the value of their own toy $(M=0.95,95 \% \mathrm{CI}=[0.38,1.52])$ but not the experimenter's toy $(M=-0.07,95 \% C I=[-0.74,0.59], t(19)=3.56$, $p=0.01, d=0.81$, Bonferroni corrected). The opposite pattern of responses were observed in the other-focus condition, in which children valued the experimenter's toy higher $(M=0.86,95 \% \mathrm{CI}=$ $[0.20,1.51])$, but not their own toy $(M=0.17,95 \% \mathrm{CI}=[-0.39$, $0.73])$ - although this effect was not statistically significant $(t$ $(19)=-1.61, p=0.36, d=0.48$, Bonferroni corrected). There was no significant effect of toy owner in the neutral-focus condition $\left(M_{\text {child }}=0.89,95 \% \mathrm{CI}_{\text {child }}=[0.31,1.46], M_{\text {experimenter }}=0.71,95 \%\right.$ $\left.\mathrm{Cl}_{\text {experimenter }}=[0.04,1.38], t(19)=0.48, p=0.64, d=0.13\right)$. The mean value change scores for each condition as a function of toy owner are presented in Fig. 2. We found no significant main effects of types of picture type $\left(M_{\text {self }}=0.44,95 \% \mathrm{CI}_{\text {self }}=[-0.04,0.91]\right.$, $M_{\text {other }}=0.51,95 \% \mathrm{Cl}_{\text {other }}=[0.04,0.98], M_{\text {neutral }}=0.80,95 \% \mathrm{Cl}_{\text {neutral }}=$ $\left.[0.32,1.28], F(2,53)=0.61, p=0.55, \eta_{p}^{2}=0.02\right)$ or toy owner $\left(M_{\text {child }}=0.67,95 \% \quad \mathrm{CI}_{\text {child }}=[0.34,0.99], \quad M_{\text {experimenter }}=0.50,95 \%\right.$ $\left.\mathrm{Cl}_{\text {experimenter }}=\left[\begin{array}{ll}0.12, & 0.89\end{array}\right], \quad F(1,53)=0.55, \quad p=0.46, \quad \eta_{p}^{2}=0.01\right)$.
A significant effect of age was observed $(F(1,53)=7.68, p=0.01$, $\left.\eta_{p}^{2}=0.13\right)$, indicating that older children increased their valuations more than younger children regardless of toy owner or picture condition. No significant effect of gender $(F(1,53)=0.46, p=0.50$, $\left.\eta_{p}^{2}=0.01\right)$, and no significant interactions involving gender or age were observed ( $F s<2.69, p s>0.11$, etc.).

Value changes for the control object were also assessed in the three picture construction conditions to ensure that the picture focus manipulation had a specific effect on endowment objects, rather than a general effect on children's object valuation. There was no significant effects of picture construction condition ( $F$ $\left.(2,53)=0.43, p=0.70, \eta_{p}^{2}=0.29\right)$, gender $(F(1,53)=1.71, p=0.33$, $\left.\eta_{p}^{2}=0.47\right)$, or age $\left(F(1,53)=1.10, p=0.30, \eta_{p}^{2}=0.02\right)$ and no significant interactions between these variables on value change scores for the control item. This indicates that picture focus did not generally affect children's valuation of objects, but was specific to the endowment objects.

Children's reluctance to trade their endowed toy for the experimenter's identical toy was compared across the three picture construction conditions. Seventeen children (85\%) were reluctant to trade after self-focus, 8 children (40\%) after other-focus, and 16 children (80\%) after neutral focus (see Fig. 3). Children's trading behaviour differed significantly across the three conditions $\left(\chi^{2}(2\right.$, $N=60)=11.24, p=0.004, \phi=0.43$ ). Pairwise comparisons confirmed that children were less willing to trade following selffocus and neutral-focus compared to other-focus (self: $Z=-2.90$, $p=0.004$; neutral: $Z=-2.55, p=0.01$ ) but there was no difference in reluctance to trade between self- and neutral-focus conditions $(Z=-0.41, p=0.68)$. These findings suggest that children were reluctant to give up items in their possession and only after other-focus did trading rates increase.

Following self-focus, the value of a child's own toy increased in comparison to an identical toy owned by the experimenter. Children were also less willing to trade toys in this condition. As predicted, completing a self-focused activity can induce increased valuation of own possessions in young children, lending support to the extended-self explanation of endowment effects. In the other-focus condition, although the value of the experimenter's toy did not increase significantly more than the child's toy, children were more willing to trade their toy for the other. Children may have been inclined to swap with the experimenter because the other-focus activity may have alerted them to another's needs so that when a specific other proposed a trade, they were inclined to oblige. Alternatively, other-focus priming could have made them more willing to trade items in general; possibly as a consequence of less self-centred focus. To test this, we decided to conduct a second study where the identical object for valuation and trading was not owned.

\section{Study 2}

Study 2 aimed to test whether the changes in object valuation following self- and other-focus as well as the differences in children's trading behaviour were influenced by the fact that the other object was owned by the experimenter. We thus tested a new sample of preschoolers and included an unowned object as comparison. As there were no effects in the neutral focus condition, it was not included in Study 2.

\subsection{Materials and method}

\subsubsection{Participants}

40 three-to-four-year-olds $\left(M_{\text {age }}=47.28\right.$ months, $S D_{\text {age }}=6.49$, range $=36-58$ months; 21 female) participated in Study 2 . None of these participants had previously completed Study 1 . Three 


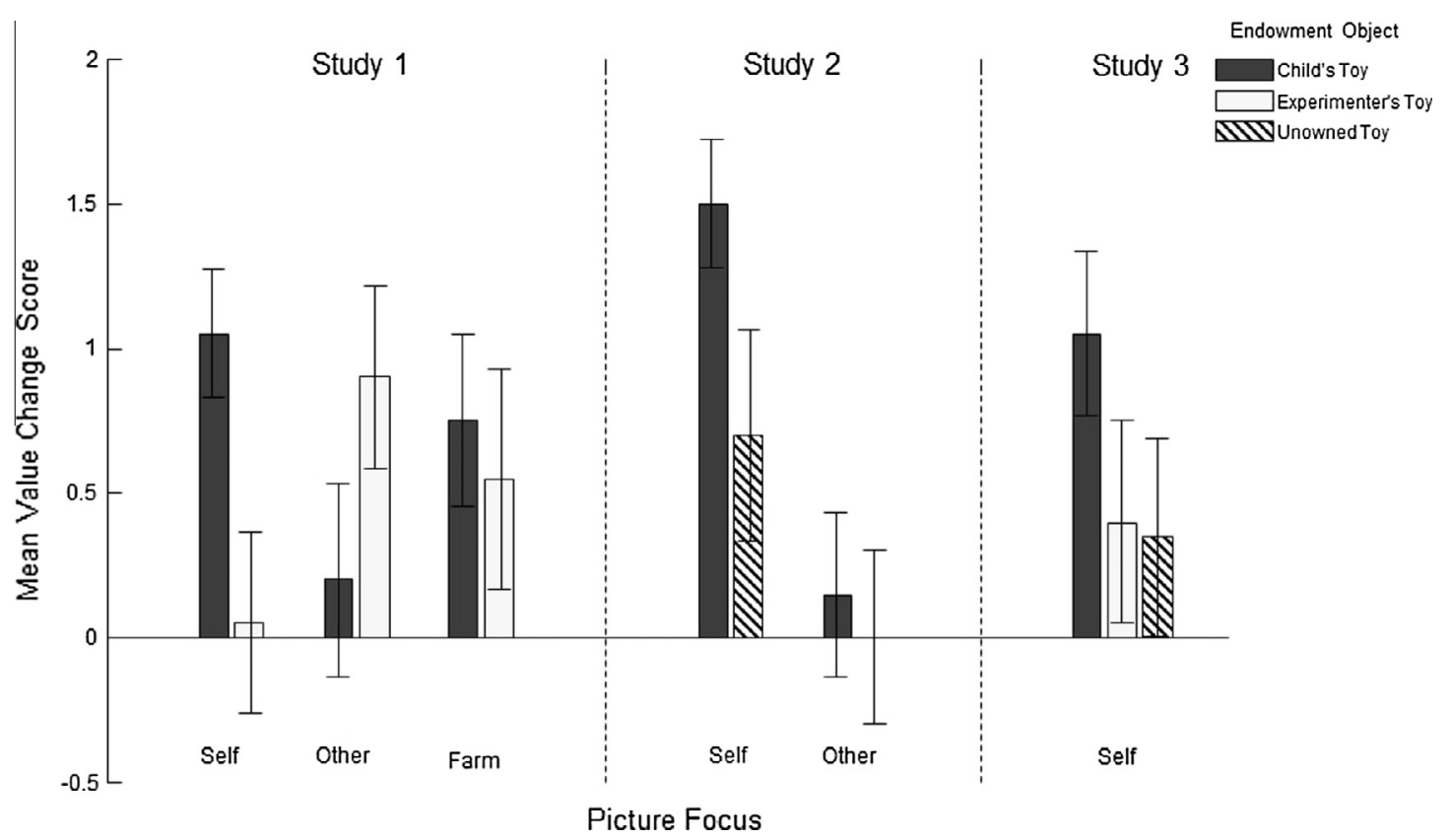

Fig. 2. Mean value change scores for each object as a function of picture focus. Error bars represent \pm 1 SEM.

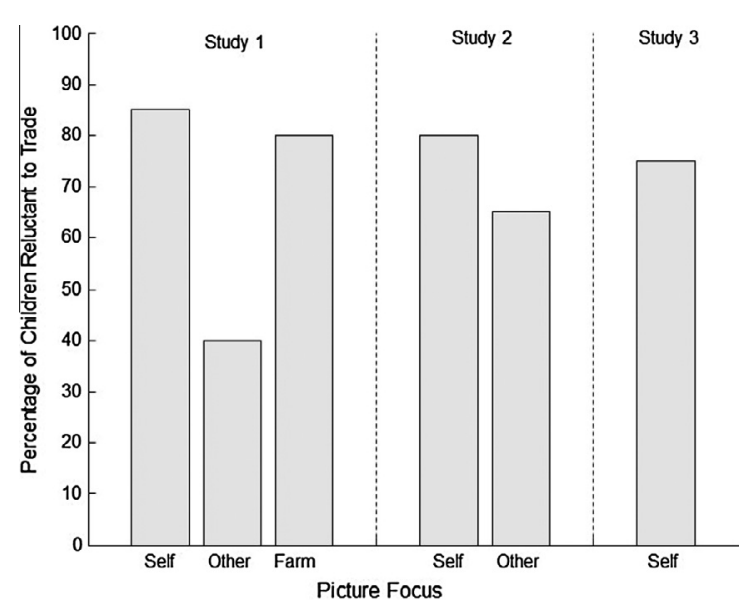

Fig. 3. Percentage of children reluctant to trade their object for an identical object as a function of picture focus.

additional children were tested but excluded from analysis because they failed to understand the smiley-scale $(n=1)$, or failed to pass the equality test $(n=2)$.

\subsection{Procedure}

The procedure was identical to study 1 , with the exception that the identical spin-toy was not labelled as belonging to the experimenter, but was simply left on the table (in the child's view but out of its reach). In addition, children only completed either the self- or other-focus picture construction task (no neutral focus).

\subsubsection{Data scoring and preliminary analyses}

Data scoring and analyses were identical to study 1 . The amount of time spent on the picture construction task was calculated from the video data. Unfortunately this information was not available for 3 children in the self- and 2 children in the other-focus conditions due to experimenter error. Time spent on the picture construction task in the remaining 35 children did not differ significantly between self- $(M=228.53,95 \% \mathrm{CI}=$ $[216.28,240.78])$ and other- $(M=231.11,95 \% \mathrm{CI}=[219.20$, $243.02])$ picture types $(t(33)=0.36, p=0.72, d=0.12)$. In addition the experimenter's use of second person pronouns during selffocus and of third person pronouns during other-focus did not differ significantly $\quad\left(M_{\text {self }}=33.24, \quad 95 \% \quad \mathrm{CI}=[32.01,34.46]\right.$; $M_{\text {other }}=33.50,95 \% \mathrm{CI}=[32.31,34.69], \quad(t(33)=0.30, p=0.76$, $d=0.10$ ).

\subsection{Results}

Children who completed the self-focus task increased the value of both identical objects more $(M=1.13,95 \% \mathrm{CI}=[0.59,1.68])$, than children who completed the other-focus task $(M=0.06,95 \% \mathrm{CI}=$ $\left.[-0.49,0.60], F(1,35)=7.89, p=0.008, \eta_{p}^{2}=0.18\right)$. In addition, children increased the valuation of their own object $(M=0.83,95 \%$ $\mathrm{CI}=[0.45,1.21])$ more than their valuation of the unowned endowment object $(M=0.36,95 \% C I=[-0.12,0.85], \quad F(1,35)=4.97$, $\left.p=0.03, \eta_{p}^{2}=0.12\right)$. In contrast to Study 1 , the interaction between ownership and picture type was not significant $(F(1,35)=1.71$, $\left.p=0.20, \eta_{p}^{2}=0.05\right)$. However, a planned comparisons $t$-test confirmed that children continued to increase the value of their own object more than that of the identical, unowned object following self-focus $(\mathrm{t}(19)=2.71, \mathrm{p}=0.01, d=0.55$; see Fig. 2 ). No other factors or interactions were statistically significant. Value change scores for the control object, were not significantly affected by picture type $\left(F(1,35)=0.11, p=0.79, \eta_{p}^{2}=0.10\right)$, gender $(F(1,35)$ $\left.=0.05, \quad p=0.86, \quad \eta_{p}^{2}=0.05\right)$, or age $(F(1,35)=0.29, p=0.60$, $\left.\eta_{p}^{2}=0.01\right)$. Finally, 16 children (80\%) refused to swap their toy following self-focus and 13 (65\%) refused to swap following otherfocus (see Fig. 3). The difference in swapping behaviour between picture types was not significant $\left(\chi^{2}(1, N=40)=1.13, p=0.48, \phi\right.$ $=0.17$ ).

The findings from Study 2 replicated the effects observed in Study 1 following self-focus. This time other-focus did not produce increased valuation of an unowned, identical object and swapping behaviour was also reduced. The reduction in swapping behaviour compared to Study 1 probably arose because the toy was unowned 
in this case. In Study 1, the experimenter who owned the toy, requested the swap adding social pressure for the child to comply. This suggests that the other-focus did not produce an effect that generalized to trading for unowned toys. A main effect of picture type in Study 2 suggested that self-focus raised the value of the unowned object as well as the value of the owned object. One possibility for this pattern was that in the absence of ownership, the value of the identical, unowned object was anchored to the selfowned object in the self-focus condition because of its physical resemblance. To investigate this further, we conducted a third study looking at the effects of self-focus on three categories of object, self-owned, experimenter-owned and unowned.

\section{Study 3}

So far our findings suggested that attention focus affected children's object valuations differently depending on the object's ownership. Yet, our studies only contrasted self- vs other-owned (Study 1 ) or self-owned vs unowned (Study 2), so in Study 3 we set out to directly compare the effects of self-focus on self-owned, otherowned and unowned objects using within-subjects comparison for each child.

We expected to replicate the self-focus effect on the child's valuation of their owned toy relative to the experimenter's object and the unowned object, but had no prediction as to whether self-focus would lead to a differentiation between the latter two. For example, I may value my pen more than the one belonging to my classmate, but I may consider an unowned pen as more valuable because of my potential for owning it. Alternatively I may covet my classmate's pen more, because in owning it, I have what is theirs, thereby diminishing their worth. As noted earlier preschool children tend to want what others have (Shantz, 1987). Still we had no a priori assumption with regard to the direction of a difference if found.

\subsection{Materials and method}

\subsubsection{Participants}

20 three-to-four-year-olds $\left(M_{\text {age }}=49.40\right.$ months, $S D=5.54$, range $=40-58$ months; 10 female) participated in Study 3. None of these participants had previously completed Study 1 or Study 2. Three additional children were tested but excluded from analysis because they failed to understand the smiley-scale $(n=2)$, or failed to pass the equality test $(n=1)$.

\subsection{Procedure}

The procedure for Study 3 was identical to the previous studies except there were three identical spin-top toys. One was allocated to the child, one to the experimenter, and the third object remained unallocated. In addition, children only completed the self-focus task before being asked to value the three items in a counterbalanced order once again. Finally, the child was asked if they would like to keep their toy or swap for the experimenter's toy.

\subsubsection{Data scoring and preliminary analyses}

Once again, the amount of time spent on the picture construction task $(M=232.00 \mathrm{~s}, 95 \% \mathrm{CI}=[220.70,243.30])$ and the number of second person pronouns used by the experimenter during the task $(M=33.70,95 \% \mathrm{CI}=[32.57,34.83])$ was recorded from video and did not differ significantly from any of the picture construction tasks used in Studies 1 or 2 (time: $F(5,109)=0.28, p=0.92$, $\eta_{p}^{2}=0.01$; pronouns: $\left.F(4,90)=0.19, p=0.94, \eta_{p}^{2}=0.01\right)$.

\subsection{Results}

Children's valuation changes for three identical objects was significantly moderated by ownership $(F(2,34)=3.41, p=0.045$, $\left.\eta_{p}^{2}=0.17\right)$. Bonferroni corrected, paired samples t-tests revealed that children increased the value of their own item $(M=1.10$, $95 \% \mathrm{CI}=[0.42,1.68])$ more than the unowned item $(M=0.35$, $95 \% \mathrm{CI}=[-0.41,1.11], t(19)=2.77, p=0.04, d=0.49)$. However, the value increase for their own item compared to the experimenter's item $(\mathrm{M}=0.40,95 \% \mathrm{CI}=[-0.38,1.18])$ was only trending in significance $(t(19)=1.99, p=0.06, d=0.45)$. There was no difference in value change scores between the experimenter's and the unowned item $(t(19)=0.18, p=0.86, d=0.03)$. No main effect of gender $\left(F(1,17)=0.01, p=0.89, \eta_{p}^{2}=0.001\right)$ or age $(F(1,17)=0.08$, $\left.p=0.79, \eta_{p}^{2}=0.004\right)$ and no interactions with gender or age were significant. Fifteen children (75\%) refused to swap their toy for the experimenter's toy at the end of Study 3. This is comparable with the swapping data from self-focus conditions in Studies 1 and $2\left(\chi^{2}(2, N=60)=0.63, p=0.92, \phi=0.10\right)$.

Overall, Study 3 replicated the increase in valuation for owned toys following self-focus and showed that this effect was specific to the child's owned object. Children were also reluctant to swap their toy for the one owned by the experimenter at levels found in Studies 1 and 2. We also demonstrated that self-focus had no differential impact on the way in which other-owned and unowned objects were valued, suggesting that children treated them equivalently. Therefore the contribution of Study 3 was to replicate the self-focus effect on endowment value and trading for possession, though we did not find a differential evaluation of items belonging to others compared to those that were unowned.

\section{General discussion}

The endowment effect is a bias to overvalue owned relative to unowned possessions. While our previous attempts to establish this effect in preschoolers have failed (Kanngiesser, 2012) this is the first study to demonstrate that preschoolers will show the endowment effect if their attention is focused on themselves in a portrait construction task. Our results are consistent with the "extended self" hypothesis (Belk, 1988) in that self-focus led to an increased evaluation of own possessions as compared to another's or no-one's (identical) possession across all three studies. Manipulations of self-focus are thus not only successful in changing adults' perceptions of an object's value (e.g., Maddux et al., 2010), but also effective in young children who have previously not been shown to exhibit an increase in valuation of possessions following endowment.

Unlike previous studies of preschoolers assessing object preferences (Gelman et al., 2012), we developed a scaling measure to assess relative changes in perceived liking before and after the attention focus manipulation to test the hypothesis that selffocus increases the subjective liking of possessions. We believed this was a critical point in establishing a change in relative worth that was triggered by a cognitive bias rather than a preference associated with the protocols related to allocation by adults; or in colloquial parental words, "You'll like what you're given, or have nothing." In fact, our findings in Study 1 (neutral farm scene) indicate that experimenter allocation alone did not lead children to value their own toy more than the experimenter's identical toy.

One recent integrative account of the endowment effect includes attentional and memory biases which explains not only the size of the endowment effect, but mitigation of the endowment effect when individuals are directed to consider frame consistent and inconsistent information (Morewedge \& Giblin, 2015). For example, attentional biases directed towards objects are triggered 
as soon as the object comes into possession leading to enhanced memory for possessions relative to non-possessions (Turk et al., 2011). Similarly, we believe that our self-focus picture task operates on children through a consistent self-framing effect.

How does self-focus induce an endowment effect? As noted in the introduction, this bias could arise from a mechanism whereby evaluations of possessions depend on evaluations of the self (Gawronski et al., 2007; Weiss \& Johar, 2013). Most people on average hold a positive self image, which may explain why they are more inclined to over-value personal possessions as a correlate of a general positive self-image (von Hippel \& Trivers, 2011). Conversely, when ownership of a good is associated with a negative self-reference such as a dunce's cap or "booby prize" for coming last in a competition, owners do not typically value it (Loewenstein \& Issacharoff, 1994).

However, an alternative related possibility is that our self-focus portrait condition increased self-esteem - a mechanism that has been shown to increase pro-sociality in 5-year-olds in hypothetical lending scenarios (Diesendruck \& Perez, 2015). Of course, raising self-esteem is more than simply self-focus - it is also making someone feel good about themselves. We cannot rule out the possibility that self-esteem was indeed raised in our self-portrait condition but we think this is unlikely to explain our pattern of results for two reasons. First, children received positive appraisal from the experimenter in all three picture construction tasks. Second, we consistently found an increased reluctance to trade items with the experimenter in the self-portrait condition which is contrary to a self-esteem account that would predict increased trading. We acknowledge that our children were one to two years younger than those in the Diesendruck and Perez (2015) study so it is possible that with age, self-esteem and self-focus begin to interact. Future studies could address these issues by manipulating both self-focus and selfesteem, for example by combining a self-portrait construction task with either positive or negative appraisal.

Interestingly, our findings cannot be explained by a simple congruency between the focus of the prime and the owner of an object. While a congruency was given in the self-prime and selfowned condition, the other-focus priming consisted of constructing a picture of a sibling or friend and increased the value of the experimenter-owned object. The only way in which this could be viewed as a congruency is if children are categorizing objects as 'mine' vs 'owned by other' where the identity of the owner does not matter. Previous work has shown that children of this age already have more sophisticated ownership concepts than just self-owned vs other-owned, distinguishing between different owners under a variety of circumstances (Friedman \& Neary, 2008).

Focusing on others during the picture construction task led to a decrease in valuation of self-owned possessions (and a nonsignificant increase in valuation of other's possessions) as well as increases in trading rates. These findings are subtle indicators that increasing focus away from one's own possession could lead to a greater appreciation of other's property. In contrast, we found no evidence that other-focus led to an increase in valuation of unowned possessions in Study 2 suggesting that ownership was a necessary prerequisite for the bias to operate. This represents a potentially interesting line enquiry into how we develop attitudes to communal obligations and pro-sociality in general.

Developmentally, there is a shift towards less selfish behaviour. Usually, there is a tendency in children of this age to hold onto their possessions and not share resources. For example, in the dictator game, young children have a tendency to maximize self-gain and it is not until they are five years and older that they begin to share resources equally (Blake \& Rand, 2010; Gummerum, Hanoch, Keller, Parsons, \& Hummel, 2010). Less than 10\% of three- to fouryear-olds will maximize another's resources even when there is no cost to sharing (Fehr, Bernhard, \& Rockenbach, 2008). Focusing young children's attention on others may ameliorate these effects and counteract young children's self-maximizing tendencies.

Throughout our studies, we used identical objects for evaluation and trading. As noted earlier, adult studies on endowment effect have used non-identical, but equally preferred objects. In violation of standard theory of choice, reluctance to trade endowed objects has been reliably observed in adults and children over six years of age in these non-identical situations (Harbaugh et al., 2001; Thaler, 1980). We found in our study that young children's default for trading identical objects (i.e. their trading in the neutral-focus condition) was to refrain from swapping their object. It is possible, however, that children refrained from trading not because of endowment effects but because trading involved a small cost. In fact, adult studies found that subjects were only willing to trade for an identical item, when they were compensated with financial incentive for trading costs (Chapman, 1998, Experiment 4; Bar-Hillel \& Neter, 1996). To our knowledge, no adult study to date has looked at endowment effects for identical objects without controlling for transaction costs. However, the one study that has looked at the role of object similarity in the endowment effect, found no differences in trading between similar and dissimilar items (Chapman, 1998). There is however, one notable exception in which to adult evaluations of identical objects can differ as a function of ownership - the value of celebrity memorabilia based on the belief that objects were owned and touched by someone famous (Gjersoe, Newman, Chituc, \& Hood, 2014).

We believe that the use of identical items was very important for an object evaluation measure as it eliminated noise from individual preferences. Moreover, it added weight to our interpretation that ownership conferred additional value to an otherwise physically identical object. Systematic differences in how the identical objects were evaluated in our studies were a clear indication that these effects were not due to superficial object properties but to the effectiveness of the self- or other-focus task.

In conclusion, we have provided the first evidence of an endowment effect in preschool children that manifests as a change in evaluation of an owned object that was triggered by a task that focused their attention on themselves. We also produced evidence that focusing on another person generally produced the opposite profile. Children at this age are also notoriously reluctant to swap or share but we were able to increase this activity by getting them to focus on another during a picture construction of a friend or a sibling. We think that our task worked primarily by manipulating the focus of attention onto the self though there may be other related psychological processes operating. What remains to be seen is the extent to which other forms of self-focus can induce this effect. This work adds to the growing body of research that there is an integral relationship between our self-concept and possessions, which will probably reflect cultural attitudes towards ownership that children adopt during development.

\section{Acknowledgements}

This research was supported by an ESRC - United Kingdom Grant ES/K010131/1 awarded to the first author. We are indebted to Dr Philip Collard for helping with the statistical analysis. We gratefully acknowledge the support of the At-Bristol Science Museum and willingness of parents to participate with their children in testing at the Bristol Cognitive Development Centre.

\section{Appendix A. Supplementary material}

Supplementary data associated with this article can be found, in the online version, at http://dx.doi.org/10.1016/j.cognition.2016. 03.019. 


\section{References}

Bar-Hillel, M., \& Neter, E. (1996). Why are people reluctant to exchange lottery tickets? Journal of Personality and Social Psychology, 70, 17-27.

Beaman, A. L., Diener, E., \& Klentz, B. (1979). Self-awareness and transgression in children: Two field studies. Journal of Personality and Social Psychology, 37, 1835-1846.

Belk, R. W. (1988). Possession and the extended self. Journal of Consumer Research, $15,139-168$

Berti, A. E., \& Bombi, A. S. (1981). The development of the concept of money and its value: A longitudinal study. Child Development, 52, 1179-1182.

Blake, P., \& Rand, D. (2010). Currency value moderates equity preference among young children. Evolution and Human Behavior, 31, 210-218.

Carmon, Z., \& Ariely, D. (2000). Focusing on the forgone: How value can appear so different to buyers and sellers. Journal of Consumer Research, 27, 360-370.

Chapman, G. B. (1998). Similarity and reluctance to trade. Journal of Behavioral Decision Making, 11, 47-58.

Diener, E., \& Wallbom, M. (1976). Effects of self-awareness on anti-normative behaviour. Journal of Research in Personality, 10, 107-111.

Diesendruck, G., \& Perez, R. (2015). Toys are me: Children's extension of self to objects. Cognition, 134, 11-20.

Fasig, L. G. (2000). Toddlers' understanding of ownership: Implications for selfconcept development. Social Development, 9, 370-382.

Fehr, E., Bernhard, H., \& Rockenbach, B. (2008). Egalitarianism in young children. Nature, 454, 1079-1083.

Ferraro, R., Escalas, J. E., \& Bettman, J. R. (2011). Our possessions, our selves: Domains of self-worth and the possession-self link. Journal of Consumer Psychology, 21, 169-177.

Friedman, O., \& Neary, K. R. (2008). Determining who owns what: Do children infer ownership from first possession? Cognition, 107, 829-849.

Gawronski, B., Bodenhausen, G. V., \& Becker, A. P. (2007). I like it, because I like myself: Associative self-anchoring and post-decisional change of implicit evaluations. Journal of Experimental Social Psychology, 43, 221-232.

Gelman, S. A., Manczak, E. M., \& Noles, N. S. (2012). The nonobvious basis of ownership: Preschool children trace the history and value of owned objects. Child Development, 83, 1732-1747.

Gjersoe, N. L., Newman, G. E., Chituc, V., \& Hood, B. (2014). Individualism and the extended-self: Cross-cultural differences in the valuation of authentic objects. PLoS One, 9, e90787.

Gummerum, M., Hanoch, Y., Keller, M., Parsons, K., \& Hummel, A. (2010) Preschoolers' allocations in the dictator game: The role of moral emotions. Journal of Economic Psychology, 31, 25-34.

Harbaugh, W. T., Krause, K., \& Vesterlund, L. (2001). Are adults better behaved than children? Age, experience, and the endowment effect. Economics Letters, 70 , $175-181$.
Hay, D. F. (2006). Yours and mine: Toddlers' talk about possessions with familiar peers. British Journal of Developmental Psychology, 24, 39-52.

Hood, B., \& Bloom, P. (2008). Children prefer certain individuals to perfect duplicates. Cognition, 106, 455-462.

Hoorens, V., Remmers, N., \& van de Riet, K. (1999). Time is an amazingly variable amount of money: Endowment and ownership effects in the subjective value of working time. Journal of Economic Psychology, 20, 383-405.

James, W. (1890). The principles of psychology.New York: H. Holt and Company.

Kahneman, D., \& Tversky, A. (1979). Prospect theory: An analysis of decision under risk. Econometrica, 47, 263-291.

Kanngiesser, P. (2012). Biological and developmental origins of ownership concepts Unpublished Ph.D thesis. University of Bristol.

Kanngiesser, P., Gjersoe, N. L., \& Hood, B. (2010). The effect of creative labor on property- ownership transfer by preschool children and adults. Psychological Science, 21, 1236-1241.

Knetsch, J. L. (1989). The endowment effect and evidence of nonreversible indifference curves. The American Economic Review, 79, 1277-1284.

Levine, L. E. (1983). Mine: Self-definition in 2-year-old boys. Developmental Psychology, 19, 544-549.

Loewenstein, G., \& Issacharoff, S. (1994). Source dependence in the valuation of objects. Journal of Behavioral Decision Making, 7, 157-168.

Maddux, W. W., Yang, H., Falk, C., Adam, H., Adair, W., Endo, Y., Carmon, Z., \& Heine, S. J. (2010). For whom is parting with possessions more painful? Cultural differences in the endowment effect. Psychological Science, 21, 1910-1917.

Morewedge, C. K., \& Giblin, C. E. (2015). Explanations of the endowment effect: An integrative review. Trends in Cognitive Science, 19, 339-348.

Morewedge, C. K., Shu, L., Gilbert, D., \& Wilson, T. (2009). Bad riddance or good rubbish? Ownership and not loss aversion causes the endowment effect. Journal of Experimental Social Psychology, 45, 947-951.

Rossano, F., Rakoczy, H., \& Tomasello, M. (2011). Young children's understanding of violations of property rights. Cognition, 121, 219-227.

Shantz, C. U. (1987). Conflicts between children. Child Development, 58, 283-305.

Thaler, R. H. (1980). Toward a positive theory of consumer choice. Journal of Economic Behavior and Organization, 1, 39-60.

Turk, D. J., van Bussel, K., Brebner, J. L., Toma, A., Krigolson, O., \& Handy, T. C. (2011). When IT becomes MINE: Attentional biases triggered by object ownership. Journal of Cognitive Neuroscience, 23, 3725-3733.

Vasalou, A., Joinson, A., \& Pitt, J. (2007). Constructing my online self: Avatars that increase self-focused attention. In Proceedings of ACM conference human factors in computing systems (CHI), San Jose, USA (pp. 445-448).

von Hippel, W., \& Trivers, R. (2011). The evolution and psychology of self-deception. Behavioral and Brain Sciences, 34, 1-56.

Weiss, J., \& Johar, G. V. (2013). Egocentric categorization and product judgment: Seeing your traits in what you own (and their opposite in what you don't). Journal of Consumer Research, 40, 185-201. 